\title{
An unusual presentation of parotid abscess: otorrhea
}

\begin{abstract}
Acute suppurative parotitis and parotid gland abscess are infrequently seen in children. Ductal ectasis, primary parenchymal involvement or from a suppurative infection of the lymph nodes cause suppurative changes and leads to abcess formation. Various bacteria have been reported to be involved in the bacterial parotitis and abscesses; Staphylococcus aureus plays a major role both in adults, and in pediatrics patients, while in infant recurrent parotitis, Streptococcus spp. are the most recurrent isolated organisms. The pus may penetrates the capsule, invades the surrounding tissue, and extends into the deep fascial planes, backward into the external auditory canal as in our case, or outward into the facial skin.
\end{abstract}

Keywords: parotid abscess, otorrhea
Volume 2 Issue 3 - 2015

\section{Merih Onal, Gultekin Ovet, Necat Alatas \\ Department of Otorhinolaryngology, Konya Education and Training Hospital,Turkey}

\section{Correspondence: Merih Onal, Department of}

Otorhinolaryngology, Konya Education and Training Hospital, Konya, Turkey, Tel +905554376238,

Emaildrmerihonal@gmail.com

Received: March 30, 2015 | Published: May 12, 2015

\section{Introduction}

Acute suppurative parotitis and parotid gland abscess are infrequently seen in children. Bacterial or viral infection of intraparotideal and periparotideal lymph nodes or the glandular parenchyma can give rise to inflammatory reactions. Ductal ectasis, primary parenchymal involvement or from a suppurative infection of the lymph nodes cause suppurative changes and leads to abcess formation. A parotid abscess can give rise to life-threatening complications, like fasciitis or deeper head and neck abscesses. The pus penetrates the capsule, invades the surrounding tissue, and extends into the deep fascial planes, backward into the external auditory canal, or outward into the facial skin. This case illustrates the unusual manifestation of parotid abscess encountered as external otitis .

\section{Case}

17 month old infant with complaints of right ear discharge was admitted to the pediatric clinic. Patient with a diagnosis of external otitis declared by pediatrician was started a therapy with ear drop of ciprofloxacin and dexamethasone. Patient's complaints did not decrease despite medical therapy. Minimal swelling in the right parotid region was discovered by the patient's pediatrician so the patient was referred to our clinic with the swelling in the parotid region. At the tenth day of swelling, when pressure is applied to the patient's parotis region, it was seen that pus was drained from the parotis to the external ear canal. Thus parotid abscess was found to be drained into the outer ear canal. Cultures were obtained from the discharge. The patient underwent parotid ultrasound. In ultrasound examination, a $3 \mathrm{~cm}$ collection detected which was localized at the deep lobe of parotid gland and extending into the postauricular region. The patient was hospitalized. Initial laboratory tests showed a total white cell count of $7.63 \mathrm{~K} / \mathrm{uL}$ and sedimentation rate was $42 \mathrm{~mm} / \mathrm{hr}$. Temporal CT findings supported the USG findings (Figure $1 \&$ Figure 2). An incision was made to the overlying skin and the abscess was drained (Figure 3). A penrose drain was placed and followed-up daily. The lesion regressed and there was no need for more radical surgery. Staphylococcus epidermidis which was resistant to most of antibiotics was isolated on culture. Teicoplanin at $10 \mathrm{mg} / \mathrm{kg} / \mathrm{dose}$ was added to treatment protocol. Ten days of antibiotic therapy resulted in complete recovery and the patient was discharged. The first follow-up visit took place within 1month and he was symptom-free except a scar tissue where the abscess was drained.

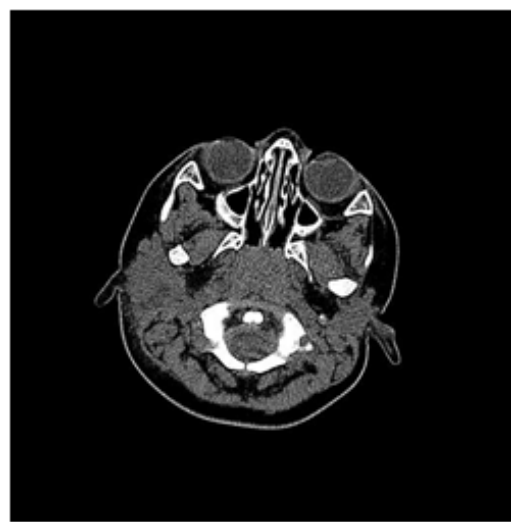

Figure I Right parotid abscess seen in CT scan.

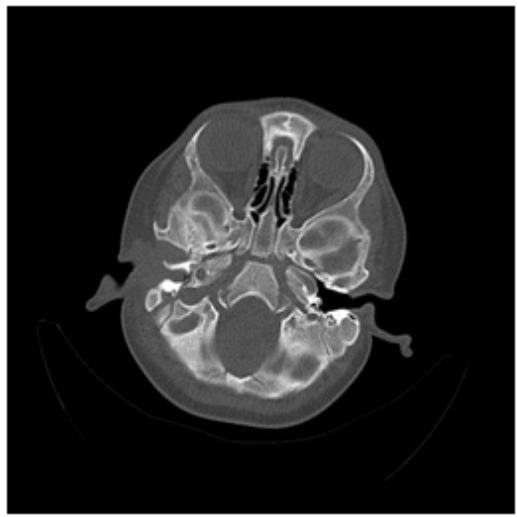

Figure 2 Abscess extending into external auditory meatus. 


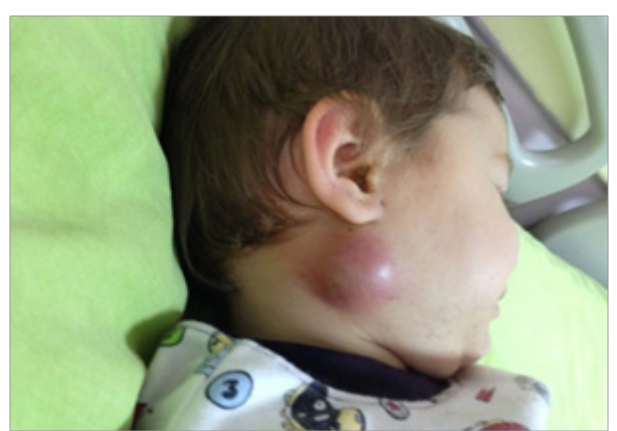

Figure 3 An incision was made to the overlying skin and the abscess was drained.

\section{Discussion}

Direct extension of microorganisms via Stensen's duct from the buccal mucosa results in salivary gland infection. ${ }^{1}$ Penetration of the bacteria leads to erosion of the duct and exudate into the parenchyma. This results in glandular destruction. ${ }^{2}$ In children, few reports of parotid abscesses exist. Various bacteria have been reported to be involved in the bacterial parotitis and abscesses; Staphylococcus aureus $^{3}$ plays a major role both in adults, and in pediatrics patients, while in infant recurrent parotitis, Streptococcus spp. are the most recurrent isolated organisms. ${ }^{4}$ In our patient, Staphylococcus epidermidis was cultured. Other implicated bacterias are Hemophilus, Pseudomonas, Mycobacterium tuberculosis, anaerobic bacteria and others. Viral agents associated with parotid gland infection are mumps (commonest), Cytomegalovirus, HIV, Epstein-Barr virus, influenza, and parainfluenza. ${ }^{5}$ There is even one case report of a candidal parotid abscess. $^{6}$

The predisposing conditions of acute suppurative parotitis include dehydration, poor oral hygiene, dental infection, oral trauma, ductal obstruction, immunosuppression, certain drugs (anticholinergics and antihistamines), certain chronic diseases (Sjogren's syndrome and diabetes mellitus), malnutrition, pre-existing parotid Warthin's tumor, and sialolithiasis. ${ }^{7,8}$ These precipitating factors generally seen in adults. Ductal stones not seen frequently in children as in our case, correlating the fact that parotid abscess formation is related with nonobstructive origin in most cases. Our patient had no problems in oral hygiene, overall health was good. Seeding of bacteria from systemic stream was unlikely as the blood culture was sterile. He had no previous parotitis or parotid-related symptoms, it was a complication of the first episode of acute parotis. In the study of Saarinen and his colleagues, ${ }^{9,10}$ two patient which had a parotid abscess were diagnosed with a first brachial cleft fistula; each had an opening in the periauricular area with frequent secretion and a third child thought to has an undiagnosed brachial cleft, as his abscess ruptured in the ear canal. Frequent suppuration of the parotid gland can be the result of first brachial cleft fistula which is rarely seen and lead to fistula formation. However, in our patient, there is no any radiological findings suggestive of branchial cleft cyst.

The symptoms of a parotid abscess include spontaneous onset of warm, indurated, erythematous swelling of the angle of the jaw, pain for the stretching of the dense parotid capsule, erythema of the preauricular area associated with marked fever and leukocytosis. ${ }^{5,11}$ Regional lymphadenitis may occur, as well as purulent secretion from
Stensen's duct may be exuding spontaneously, or induced by gentle massage over the gland. However, absence of purulent secretion from Stensen's duct does not exclude the disease as in our patient, purulent discharge from Stenson's duct was not demonstrable. Clinically, no pathognomic feature was defined to differentiate between glandular abscess and other types of suppurative parotitis except radiological investigations. $^{5} \mathrm{CT}$ scans and ultrasound are important imaging modalities to differentiate between acute suppurative parotitis and parotid abscess. Sonographically there is an increase in gland volume, result of the inflammatory process. Abscess formation characterized by hypo-anechoic lesion, with irregular margins. Ultrasound can distinguish between obstructive or nonobstructive sialoadenitis. ${ }^{5}$ Ultrasound imaging is also used in treatment for assistance in the surgical incision and drainage of the abscess. ${ }^{12} \mathrm{CT}$ differentiate soft tissue densities within the gland. ${ }^{13}$ and exclude possible underlying malignancy.

Abscess treatment includes broad-spectrum IV antibiotics, good oral hygiene, adequate hydration and surgical drainage is advisable. In most cases quite small procedure like drainage incisions is enough, ${ }^{4}$ posterior-based flap as for parotidectomy may be useful in extreme cases. In our case, the patient did not require radical drainage procedure. An incison was made to the abscess and drained. Optimal duration of antibiotherapy is suggested 7 to 10 days or up to resolution of the lesion. ${ }^{14}$ Medical treatment is adequate for complete recovery in most cases but our patient progressed to develop abscess requiring drainage despite effectual dose of antibiotics. Facial nerve dysfunction has been related to parotitis ${ }^{15}$ and parotid abscesses ${ }^{16}$ in adults. Fortunately, our patient did not developed facial nerve dysfunction and responded the treatment well without significant complication. Only there is a scar formation at the region of the abscess.

\section{Conclusion}

This case shows that parotid abscess may be presented with suppuration from the external ear canal. When parotid abscess in infants drained into the external auditory canal, swelling in parotid region may be minimal and diagnosis may be postponed. We emphasize that if there is no improvement in prolonged otorrhea despite appropriate treatment, infection of the salivary gland should be considered. Intravenous antibiotic therapy is the main treatment in parotid abscess, but besides this, surgical drainage may be required.

\section{Acknowledgements}

None.

\section{Conflict of interest}

The author declares no conflict of interest.

\section{References}

1. Chevalier J, Jadcherla SR. Parotid swelling in a premature neonate. Am J Perinatol. 2002;19(8):435-438.

2. Sherman JA. Pseudomonas parotid abscess. J Oral Maxillofac Surg. 2001;59(7):833-835.

3. Brook I. Acute bacterial suppurative parotitis: microbiology and management. J Craniofac Surg. 2003;14(1):37-40.

4. Nusem-Horowitz S, Wolf M, Coret A, et al. Acute suppurative parotitis a parotid abscess in children. Int J Pediatr Otorhinolayngol. 1995;32(2):123127. 
5. Tan VE, Goh BS. Parotis abscess: a five-year review--clinical presentation, diagnosis and management. J Laryngol Otol. 2007;121(9):872-879.

6. Even-Tov E, Niv A, Kraus M, et al. Candida parotitis with abscess formation. Acta Otolaryngol. 2006;126(3):334-336.

7. Marioni G, Bottin R, Tregnaghi A, et al. Craniocervical necrotizing fasciitis secondary to parotid gland abscess. Acta Otolaryngol. 2003;123(6):737740

8. Kishore R, Ramachandran K, Ngoma C, et al. Unusual complication of parotid abscess. J Laryngol Otol. 2004;118(5):388-390.

9. Kishore R, Ramachandran K, Ngoma C, et al. Unusual complication of parotid abscess. J Laryngol Otol. 2004;118(5):388-390.

10. Krippaehne WW, Hunt TK, Dunphy JE. Acute suppurative parotitis: a study of 161 cases. Ann Surg. 1962;156:251-257.

11. Saarinen RT, Kolho KL, Pitkaranta A. Cases presenting as parotid abscesses in children. Int J Pediatr Otorhinolaryngol. 2007;71(6):897-901.
12. Zurina Z, Wong HL, Jasminder K, et al. Parotid abscess in a late premature infant: a case report. Med J Malaysia. 2012;67(6):631-632.

13. Gritzmann N, Rettenbacher T, Hollerweger A, et al. Sonography of the salivary glands. Eur Radiol. 2003;13(5):964-975.

14. Fattahi TT, Lyu PE, Van Sickels JE. Management of acute suppurative parotitis. J Oral Maxillofac Surg. 2002;60(4):446-448.

15. Khan SU, O'Sullivan PG, McKiernan J. Acute Suppurative neonatal parotitis: case report. Ear Nose Throat J. 2010;89(2):90-91.

16. Andrews JC, Abemayor E, Alessi DM, et al. Parotitis and facial nerve dysfunction. Arch Otolaryngol Head Neck Surg. 1989;115(2):240-242.

17. Smith DR, Hartig GK. Complete facial paralysis as a result of parotid abscess. Otolaryngol Head Neck Surg. 1997;117(6):S114-117. 